\title{
Information on arterial properties from home blood pressure monitoring: work still in progress
}

\author{
Gianfranco Parati and Miriam Revera
}

Hypertension Research (2010) 33, 662-665; doi:10.1038/hr.2010.98

\section{DYNAMIC ASSESSMENT OF ARTERIAL DISTENSIBILITY: THE AMBULATORY ARTERIAL STIFFNESS INDEX}

A ssessment of large artery stiffness has A become increasingly popular in recent years because it may provide a relatively easyto-obtain index of vascular damage, and may thus offer a simple means for cardiovascular risk stratification, in particular in hypertensive patients. ${ }^{1-3}$ Indeed, the 2007 European Society of Hypertension-European Society of Cardiology hypertension guidelines have for the first time included arterial stiffness among the indices of subclinical organ damage carrying prognostic information. ${ }^{4}$ A number of methods have been proposed to directly and noninvasively measure regional and local arterial stiffness in human subjects at different sites along the arterial tree ${ }^{5}$ (Table 1). However, these methods are not free from methodological problems, among which is the limited accuracy of the estimates they provide. In fact, an accurate measurement of local artery stiffness would require, as an essential prerequisite, an accurate measurement of pressure as well as of the crosssectional area of the local arterial site where the measurement is taken, which is very difficult to obtain in vivo. ${ }^{6-9}$ Such a difficulty may explain why available methods to estimate arterial stiffness in a clinical setting are able to provide only indirect and imprecise measurements of this parameter. More recently, a novel indirect method to explore arterial stiffness in a dynamic way has been

Professor G Parati is at the Department of Clinical Medicine and Prevention, University of Milano-Bicocca; Centro Interuniversitario di Fisiologia Clinica e Ipertensione; and Department of Cardiology, S. Luca Hospital, Istituto Auxologico Italiano, Milan, Italy and M Revera is at the Department of Cardiology, S. Luca Hospital, Istituto Auxologico Italiano, Milan, Italy.

E-mail: gianfranco.parati@unimib.it proposed, based on the quantification of the spontaneous, time-varying, relationship between systolic and diastolic blood pressure (BP) over $24 \mathrm{~h}$. The pathophysiologic background of this method comes from the observation that anytime diastolic BP increases, systolic BP shows a parallel increase that is proportional in magnitude to the degree of arterial stiffness, being small in case of compliant vessels and large in case of stiff arteries, respectively. The opposite phenomenon, that is, the degree of diastolic $\mathrm{BP}$ increase in response to an increase in systolic BP, is taken as an indirect measure of arterial compliance. The method for dynamic arterial stiffness estimation, based on the assessment of the mutual relationship between changes in diastolic and systolic BP during a $24 \mathrm{~h}$ ambulatory BP monitoring, has been termed 'ambulatory arterial stiffness index' (AASI). ${ }^{10}$ By plotting the individual values of systolic and diastolic BP measurements obtained through $24 \mathrm{~h}$ noninvasive ambulatory BP monitoring, the slope of the linear regression of diastolic BP on systolic BP is taken as a global measure of arterial compliance, and its complement ( 1 minus the slope) has been proposed as a measure of ambulatory arterial stiffness, AASI. ${ }^{10}$ Several papers have explored the clinical value of this new index, providing some evidence that AASI is associated with preclinical target organ damage in hypertension ${ }^{11,12}$ and with an increased risk of cardiovascular mortality in hypertensive patients ${ }^{13}$ and stroke in the general population. ${ }^{14}$

Such a simplified approach to the assessment of arterial stiffness, which does not require specialized equipment and dedicated personnel, has raised great interest in the scientific and medical community. However, simplicity does not necessarily means accuracy, and a number of other papers have identified other possible determinants of AASI besides arterial rigidity, and have emphasized the limitations of this approach. In a previous paper of ours, ${ }^{15}$ we showed the occurrence of a strong dependence of AASI on the degree of nocturnal BP fall in a large cohort of 515 untreated hypertensive patients. The explanation we offered for this finding is that dipper subjects have a large number of nocturnal systolic and diastolic BP values much lower than the corresponding daytime values, and this, for mathematical reasons, increases the regression coefficient of diastolic BP on systolic BP. In contrast, non-dipper subjects tend to have a narrower range of diastolic BP values throughout the $24 \mathrm{~h}$. Thus, again as a mathematical consequence, in non-dipper subjects the coefficient of regression 'B' of diastolic over systolic BP over the $24 \mathrm{~h}$ tends to decrease, and its complement (AASI, or 1-B) tends to increase. More recently, Baumann et al. ${ }^{16}$ performed $24 \mathrm{~h}$ ambulatory BP monitoring and calculated AASI in 106 adult kidney donors, among which $29 \%$ were hypertensive patients. In agreement with our paper, their main conclusion was that AASI has a strong negative relation with nocturnal systolic and diastolic BP reduction ( $r=-0.55$ and -0.48 , respectively). Moreover, they found that a significant relation between AASI and pulse pressure, taken as a reference measure of arterial stiffness, was evident only in subjects with a normal nocturnal BP reduction (dippers), but not in non-dipper subjects.

These data confirm and extend to a predominantly normotensive population the findings of our study. ${ }^{15}$ An additional limitation of AASI has a mathematical background, too. Taking advantage of a database of 140 adult subjects, Gavish et al. ${ }^{17}$ clearly disclosed the occurrence of a relationship between 
Table 1 Selective non-invasive indices of arterial stiffness/compliance (from Schillaci and Parati ${ }^{5}$, by permission)

\begin{tabular}{|c|c|c|c|c|}
\hline Index & Method & Availability & Advantages & Disadvantages \\
\hline Elastic modulus & Ultrasound (or MRI)+BP & + & $\begin{array}{l}\text { Requires no assumptions from circulation } \\
\text { models }\end{array}$ & Requires echotracking systems or MRI \\
\hline Arterial distensibility & & & & Problems with local BP estimate \\
\hline Arterial compliance & & & & Requires considerable expertise \\
\hline PWV (carotid-femoral) & Pulse signal (any type) & ++ & Gold standard for arterial stiffness & $\begin{array}{l}\text { Lack of consistency between different } \\
\text { techniques } \\
\text { Limited accuracy in measuring distance }\end{array}$ \\
\hline PWV (brachial-ankle) & Pulse signal (any type) & +++ & Easier to measure than carotid-femoral PWV & $\begin{array}{l}\text { As above } \\
\text { Based on anomalous transit tract }\end{array}$ \\
\hline \multirow[t]{3}{*}{ Aortic augmentation index } & BP waveform & +++ & $\begin{array}{l}\text { Reflects left ventricular load and coronary } \\
\text { blood flow }\end{array}$ & Indirect index for arterial stiffness \\
\hline & & & & Needs pressure wave calibration \\
\hline & & & & $\begin{array}{l}\text { Controversial accuracy of arterial transfer } \\
\text { function }\end{array}$ \\
\hline \multirow[t]{2}{*}{ Oscillatory compliance } & BP waveform & +++ & Fast acquisition & $\begin{array}{l}\text { Needs theoretical assumptions } \\
\text { (Windkessel model) }\end{array}$ \\
\hline & & & No specific expertise & \\
\hline Brachial PP & $\mathrm{BP}$ & ++++ & Obtainable with any BP measurement & $\begin{array}{l}\text { Influenced by PP amplification, heart rate, } \\
\text { vasodilatation, SV }\end{array}$ \\
\hline \multirow[t]{2}{*}{$\mathrm{PP} / \mathrm{SV}$} & Echocardiography+BP & ++ & Integrates ventricular and vascular function & $\begin{array}{l}\text { Problems with SV calculation and } \\
\text { peripheral PP }\end{array}$ \\
\hline & & & & Based on a two-element hydraulic system \\
\hline Pulse wave arrival time (QKd) & EKG+ambulatory BP & +++ & No dedicated equipment & Influenced by height, pre-ejection time \\
\hline $\begin{array}{l}\text { Ambulatory arterial stiffness } \\
\text { index }\end{array}$ & Ambulatory BP & +++ & No dedicated equipment & $\begin{array}{l}\text { Influenced by day-night BP reduction, } \\
\text { systolic/diastolic BP correlation }\end{array}$ \\
\hline
\end{tabular}

Abbreviations: BP, blood pressure; EKG, electrocardiogram; MRI, magnetic resonance imaging; PP, pulse pressure; PWV, pulse wave velocity; QKd, interval between onset of QRS and detection of last Korotkoff sound during brachial BP measurement; SV, stroke volume.

AASI and the correlation coefficient between systolic and diastolic BP, and showed that a low correlation coefficient between systolic and diastolic BP values over the $24 \mathrm{~h}$ tends to artificially decrease B (and thus to increase AASI) when a standard asymmetrical regression is used. In other words, their data provide evidence that calculation of AASI by standard regression produces a considerable overestimation of the diastolic-on-systolic slope, which is inversely dependent on the correlation coefficient between systolic and diastolic BP. Conversely, no such artifactual relationship is found when AASI is derived from a regression model that handles both variables in a symmetrical way. On the basis of their findings, Gavish et al. ${ }^{17}$ proposed a simplified calculation of 'symmetrical' AASI, which is based on standard diastolic-on-systolic BP slope, as well as on the correlation coefficient between systolic and diastolic BP values. Both our data ${ }^{15}$ and the approach developed by Gavish et al. ${ }^{17}$ unveil the same mathematical relation between systolic and diastolic BP over $24 \mathrm{~h}$, and emphasize the important confounding effect of nocturnal BP fall on AASI calculation. As reported above, individuals with a small reduction in diastolic BP from day to night (non-dippers) tend to have a narrower range of diastolic BP values throughout the $24 \mathrm{~h}$. Thus, non-dippers tend to have a lower diastolic-on-systolic BP slope and thus a higher AASI, an artifact further emphasized in studies where a low number of BP measurements was collected at night. ${ }^{18,19}$ Taken together, the data provided by all these studies ${ }^{15-17}$ suggest that the degree of nocturnal BP reduction should always be properly considered in studies focusing on the clinical and prognostic value of AASI. ${ }^{5}$ Moreover, individuals with a large or small nocturnal diastolic BP fall also tend to have a large or small systolic BP fall, respectively, which results as a consequence in higher correlation coefficients between systolic and diastolic BP and in lower AASI values in the former and in lower correlation coefficients and in higher AASI values in the latter condition, when using standard 'asymmetrical' linear regression approaches. ${ }^{17}$ All these considerations make the symmetrical regression model proposed by Gavish et al. ${ }^{17}$ theoretically more appropriate than the standard regression proposed by Li et al. ${ }^{10}$ in estimating slope-related parameters, although it remains to be established whether AASI values obtained with the former approach maintain the clinical and prognostic impact that has been attributed to AASI calculated with standard regression.
Currently the extent to which AASI, as derived from $24 \mathrm{~h}$ ambulatory BP recordings, is a true measure of arterial stiffness, is still a controversial issue. We have recently reported that the relation between AASI and a widely accepted measure of aortic stiffness, such as pulse wave velocity, is weak and importantly affected by other factors. ${ }^{15}$ In fact, as shown above, AASI itself appears to be strongly influenced by factors unrelated to arterial stiffness, including nocturnal BP reduction and the magnitude of the correlation coefficient between diastolic and systolic BP values. Thus, further studies are needed to establish the physiological determinants of AASI, as well as its real clinical significance. Such progress in knowledge would be desirable, given that a wider implementation of conventional arterial stiffness measurement in clinical practice is presently limited by the need of dedicated and rather expensive laboratory instrumentation and of trained observers. On the other side, also the implementation of AASI on a large scale in a clinical setting may face difficulties, not only because of the above-mentioned problems related to the interpretation of its clinical value, but also due to the limited availability of ambulatory BP monitoring in general practice, to its cost and to the fact that 
patients do not invariably accept this diagnostic procedure in their daily life.

\section{AN ARTERIAL STIFFNESS INDEX FROM HOME BP MONITORING DATA}

An alternative possibility to overcome the problems associated with use of available methods for arterial stiffness assessment, might theoretically come from estimates of the relation between diastolic and systolic BP values derived from self-BP measurements at home. ${ }^{20}$ Adoption of this new solution might be favored by the increasing diffusion of home BP monitoring (HBPM) observed over the last few years. ${ }^{21}$ Such a diffusion is related to the ability of HBPM to provide multiple BP measurements away from the clinic setting in the usual living environment of each individual, and to the fact that it is less costy, more widely available and better accepted by patients than ambulatory BP monitoring. Moreover, HBPM has been shown to represent a reliable alternative to ambulatory BP monitoring for the diagnosis of white coat and masked hypertension, ${ }^{21}$ and for the prediction of target organ damage ${ }^{22-24}$ and risk of cardiovascular events ${ }^{25}$ in hypertensive patients. On the background of all these acknowledged advantages of HBPM, it is thus not surprising that the suggestion to derive an 'arterial stiffness index' from home BP measurements has raised considerable interest, in spite of being made by one study including a small number of patients only. ${ }^{20}$ The paper by Stergiou et al., ${ }^{26}$ published in this issue of Hypertension Research, offers experimental evidence on the actual ability of the slope of the regression between diastolic and systolic BP values monitored at home, defined as 'home arterial stiffness index' (HASI), to provide information similar to what offered by assessment of $24 \mathrm{~h}$ AASI. An additional objective of this study was to assess whether HASI is a reliable alternative to AASI for use in clinical practice. To this aim, data obtained from clinic BP measurements, ambulatory and HOME $\mathrm{BPM}$, recorded in the context of prospective clinical trials conducted from 1995 to 2008, were retrospectively analyzed in 483 untreated or treated adults referred to an outpatient hypertension clinic for elevated BP. The regression slope of diastolic on systolic BP was separately computed for each individual on the basis of ambulatory BP and home BP readings, respectively. AASI as well as HASI were defined as 1 minus the respective regression slope of diastolic on systolic BP. AASI was also separately computed from awake or asleep ambulatory BP recordings (daytime and nighttime AASI, respectively).
Additional calculations included the assessment of symmetrical AASI and HASI, estimated using the formula suggested by Gavish et al. ${ }^{17,27,28}$ The conclusions of this study are that HASI, although being somewhat related to AASI, displays important qualitative and quantitative differences from it. As a consequence, home BP measurements do not seem to be able to replace ambulatory BP monitoring in the assessment of the arterial stiffness index. Indeed, HASI values were higher than AASI ones, and only weakly correlated with them. Moreover, HASI values were associated with age, BP and pulse pressure, as in case of AASI, but with significantly weaker correlation coefficients. Finally, there was a poor agreement between AASI and HASI in detecting subjects with more pronounced arterial stiffness. ${ }^{26}$

Thus, Stergiou et al. ${ }^{26}$ concluded against the clinical reliability of HASI as a possible substitute of AASI, with obvious negative implications for a larger use of arterial stiffness assessment in daily practice. The strength of such conclusion is based on a few merits of this study that would need to be acknowledged. These include calculation of either AASI or HASI through both standard and symmetrical regressions, on the background of the assessment of the range of systolic and diastolic BP variations characterizing the ambulatory and home BP data sets, respectively. They also include the fact that AASI and HASI values have been computed from data obtained in the same subjects over a 2-week time, without changes in treatment, and using validated oscillometric BP monitoring devices. Finally, it is a merit of this study also the detailed discussion on the possible reasons for the differences between AASI and HASI, on the background of the intrinsic differences between $24 \mathrm{~h}$ ambulatory and home BP data. Notwithstanding these merits, a few important limitations of the study by Stergiou et al. ${ }^{26}$ would also need to be considered while interpreting its results. First of all, as acknowledged by the authors, this paper is based on a retrospective analysis of data collected in previously performed clinical trials, including treated and untreated subjects, which might have affected the results in spite of the authors' attempt to account for these problems. Another limitation, probably the more important one in this study, is the absence of any direct measure of arterial stiffness against which to assess the real clinical relevance of HASI. In this paper, the possible role of HASI as a marker of stiffness is evaluated only indirectly, by considering its relation with AASI (which is a surrogate measure of stiffness itself) or with other parameters known to be themselves in turn related to arterial stiffness, such as age, systolic BP and pulse pressure. Indeed, given that AASI may not reliably quantify arterial stiffness, ${ }^{15-17,29,30}$ only the availability of a gold standard reference, as for example aortic pulse wave velocity, acknowledged worldwide as a solid estimate of the degree of arterial stiffness, would allow to definitely clarify the actual value of HASI in reflecting arterial properties. Additional controlled longitudinal trials would also need to be performed to explore the clinical value of HASI, that is, its ability to reflect organ damage in hypertensive patients and to predict their risk of developing cardiovascular events.

While waiting for such evidence, HBPM should continue to be used only to assess outof-office BP levels, in relation to their acknowledged important value in the clinical management of hypertension. ${ }^{4}$ Conversely, information on the degree of arterial stiffness should continue to be obtained from the currently validated, although not always easily available, laboratory methods, with the possible complementary contribution by AASI, whenever correctly assessed. ${ }^{15,17}$

\section{CONFLICT OF INTEREST}

The authors declare no conflict of interest.

1 Blacher J, Safar ME, Guerin AP, Pannier B, Marchais SJ, London GM. Aortic pulse wave velocity index and mortality in end-stage renal disease. Kidney Int 2003; 63: $1852-1860$.

2 Laurent S, Boutouyrie P, Asmar R, Gautier I, Laloux B, Guize L, Ducimetiere P, Benetos A. Aortic stiffness is an independent predictor of all-cause and cardiovascular mortality in hypertensive patients. Hypertension 2001; 37: 1236-1241.

3 Laurent S, Katsahian S, Fassot C, Tropeano Al, Gautier I, Laloux B, Boutouyrie P. Aortic stiffness is an independent predictor of fatal stroke in essential hypertension. Stroke 2003; 34: 1203-1206.

4 Mancia G, De Backer G, Dominiczak A, Cifkova R, Fagard R, Germano G, Grassi G, Heagerty AM, Kjeldsen SE, Laurent S, Narkiewicz K, Ruilope L, Rynkiewicz A, Schmieder RE, Boudier HA, Zanchetti A, Vahanian A, Camm J, De Caterina R, Dean V, Dickstein K, Filippatos G, Funck-Brentano C, Hellemans I, Kristensen SD, McGregor K, Sechtem U, Silber S, Tendera M, Widimsky P, Zamorano JL, Erdine S, Kiowski W, Agabiti-Rosei E, Ambrosioni E, Lindholm LH, Viigimaa M, Adamopoulos S, Agabiti-Rosei E, Ambrosioni E, Bertomeu V, Clement D, Erdine S, Farsang C, Gaita D, Lip G, Mallion JM, Manolis AJ, Nilsson PM, O'Brien E, Ponikowski $\mathrm{P}$, Redon J, Ruschitzka F, Tamargo J, van Zwieten P, Waeber B, Williams B, Management of Arterial Hypertension of the European Society of Hypertension; European Society of Cardiology. The Task Force for the Management of Arterial Hypertension of the European Society of Hypertension (ESH) and of the European Society of Cardiology (ESC). 2007 Guidelines for the Management of Arterial Hypertension. J Hypertens 2007; 25: 1105-1187.

5 Schillaci G, Parati G. Ambulatory arterial stiffness index: merits and limitations of a simple surrogate measure of arterial compliance. J Hypertens 2008; 26: $182-185$. 
6 Stefanadis C, Stratos C, Vlachopoulos C, Marakas S, Boudoulas H, Kallikazaros I, Tsiamis E, Toutouzas K, Sioros L, Toutouzas P. Pressure-diameter relationship of the human aorta: a new method of determination by the application of a special ultrasound dimension catheter. Circulation 1995; 92: 2210-2219.

7 Safar ME, London GM, Asmar RG, Hugues CJ, Laurent SA. An indirect approach for the study of the elastic modulus of the brachial artery in patients with essential hypertension. Cardiovasc Res 1986; 20: 563-567.

8 Parati G, Bernardi L. How to assess arterial compliance in humans. J Hypertens 2006; 24: 1009-1012.

9 Laurent S, Cockcroft J, Van Bortel L, Boutouyrie P, Giannattasio C, Hayoz D, Pannier B, Vlachopoulos C, Wilkinson I, Struijker-Boudier H, European Network for Non-invasive Investigation of Large Arteries. Expert consensus document on arterial stiffness: methodological issues and clinical applications. Eur Heart $J$ 2006; 27: 2588-2605.

10 Li Y, Wang JG, Dolan E, Gao PJ, Guo HF, Nawrot T, Stanton AV, Zhu DL, O'Brien E, Staessen JA. Ambulatory arterial stiffness index derived from 24-h ambulatory blood pressure monitoring. Hypertension 2006; 47: 359-364.

11 Leoncini G, Ratto E, Viazzi F, Vaccaro V, Parodi A Falqui V, Conti N, Tomolillo C, Deferrari G, Pontremol R. Increased ambulatory arterial stiffness index is associated with target organ damage in primary hypertension. Hypertension 2006; 48: 397-403.

12 Ratto E, Leoncini G, Viazzi F, Vaccaro V, Falqui V, Parodi A, Conti N, Tomolillo C, Deferrari G, Pontremol R. Ambulatory arterial stiffness index and renal abnormalities in primary hypertension. J Hypertens 2006; 24: 2033-2038.

13 Dolan E, Thijs L, Li Y, Atkins N, McCormack P, McClory S, O'Brien E, Staessen JA, Stanton AV. Ambulatory arterial stiffness index as a predictor of cardiovascular mortality in the Dublin Outcome Study. Hypertension 2006; 47: 365-370.
14 Hansen TW, Staessen JA, Torp-Pedersen C, Rasmussen S, Li Y, Dolan E, Thijs L, Wang JG, O'Brien E, Ibsen H, Jeppesen J. Ambulatory arterial stiffness index predicts stroke in a general population. J Hypertens 2006; 24: 2247-2253.

15 Schillaci G, Parati G, Pirro M, Pucci G, Mannarino MR, Sperandini L, Mannarino E. Ambulatory arterial stiffness index is not a specific marker of reduced arterial compliance. Hypertension 2007; 49: 986-991.

16 Baumann M, Dan L, Nurnberger J, Heemann U, Witzke 0 . Association of ambulatory arterial stiffness index and brachial pulse pressure is restricted to dippers. J Hypertens 2008; 26: 210-214.

17 Gavish B, Ben-Dov IZ, Bursztyn M. The linear relationship between systolic and diastolic blood pressure monitored over $24 \mathrm{~h}$ : assessment and correlates. J Hypertens 2008; 26: 199-209.

18 Dechering DG, Adiyaman A, van der Steen M, Thien T. Interstudy variability in the ambulatory arterial stiffness index. Hypertension 2007; 50: e65.

19 Schillaci G, Pucci G, Pirro M, Parati G. Response to: interstudy variability in the ambulatory arterial stiffness index. Hypertension 2007; 50: e66.

20 Qureshi G, Lazar JM, Javaid H, Weber M, Salciccioli L. Self-measured (blood pressure) arterial stiffness index: a promising new measure of arterial stiffness. J Am Soc Hypertens 2007; 1: 347-352.

21 Parati G, Stergiou GS, Asmar R, Bilo G, de Leeuw P, Imai $\mathrm{Y}$, Kario $\mathrm{K}$, Lurbe $\mathrm{E}$, Manolis $\mathrm{A}$, Mengden $\mathrm{T}$, O'Brien E, Ohkubo T, Padfield P, Palatini P, Pickering T, Redon J, Revera M, Ruilope LM, Shennan A, Staessen JA, Tisler A, Waeber B, Zanchetti A, Mancia G, on behalf of the ESH Working Group on Blood Pressure Monitoring. European Society of Hypertension guidelines for blood pressure monitoring at home: a summary report of the Second International Consensus Conference on Home Blood Pressure Monitoring. J Hypertens 2008; 26: 1505-1526.
22 Stergiou GS, Argyraki KK, Moyssakis I, Mastorantonakis SE, Achimastos AD, Karamanos VG, Roussias LG. Home blood pressure is as reliable as ambulatory blood pressure in predicting target-organ damage in hypertension. Am J Hypertens 2007; 20: 616-621.

23 Gaborieau V, Delarche N, Gosse P. Ambulatory blood pressure monitoring versus self measurement of blood pressure at home: correlation with target organ damage. J Hypertens 2008; 26: 1919-1927.

24 Shimbo D, Pickering TG, Spruill TM, Abraham D, Schwartz JE, Gerin W. Relative utility of home, ambulatory, and office blood pressures in the prediction of end-organ damage. Am J Hypertens 2007; 20: 476-482.

25 Stergiou GS, Kalogeropoulos PG, Baibas NM. Prognostic value of home blood pressure measurement. Blood Press Monit 2007; 12: 391-392.

26 Stergiou GS, Kollias A, Rarra VC, Nasothimiou EG, Roussias LG. Arterial stiffness index based on home (HASI) versus ambulatory (AASI) blood pressure measurements. Hypertens Res 2010; 33: 731-736.

27 Gavish B, Ben-Dov IZ, Kark JD, Mekler J, Bursztyn M. The association of a simple blood pressure-independent parameter derived from ambulatory blood pressure variability with short-term mortality. Hypertens Res 2009; 32: 488-495.

28 Stergiou GS, Kollias A, Rarra VC, Roussias LG. Ambulatory Arterial Stiffness Index: reproducibility of different definitions. Am J Hypertens 2009; 23: 129-134.

29 Jerrard-Dunne P, Mahmud A, Feely J. Ambulatory arterial stiffness index, pulse wave velocity and augmentation index-interchangeable or mutually exclusive measures? J Hypertens 2008; 26: 529-534.

30 Muxfeldt ES, Fiszman R, Castelpoggi CH, Salles GF. Ambulatory arterial stiffness index or pulse pressure: which correlates better with arterial stiffness in resistant hypertension? Hypertens Res 2008; 1: 607-613. 